\title{
Comunicação organizacional e interesse público: estratégias de (in)visibilidade nas mídias sociais
}

Organizational communication and public interest: strategies of (in)visibility in social media

Comunicación organizacional e interés público: estrategias de (in)visibilidad en las redes sociales

DOI: https://doi.org/10.1590/1809-5844202128

\section{Diego Wander da Silva ${ }^{1}$}

http://orcid.org/0000-0003-0786-770X

\section{Rudimar Baldissera ${ }^{2}$}

http://orcid.org/0000-0002-8295-9543

${ }^{1}$ (Pontifícia Universidade Católica do Rio Grande do Sul, Escola de Comunicação, Artes e Design, Curso de Relações Públicas. Porto Alegre - RS, Brasil).

${ }_{2}^{2}$ (Universidade Federal do Rio Grande do Sul, Faculdade de Biblioteconomia e Comunicação, Programa de Pós-Graduação em Comunicação. Porto Alegre - RS, Brasil).

\section{Resumo}

Neste artigo, discorremos sobre comunicação organizacional com os objetivos de evidenciar estratégias acionadas pelas organizações em perspectiva de reduzir e/ou direcionar sua (in)visibilidade nas mídias sociais e de problematizar tais práticas em perspectiva do interesse público. Para isso, acionamos dados de pesquisa realizada por Da Silva (2018), que evidencia um conjunto de sete estratégias empregadas por organizações com atuação no Brasil para gestão de sua (in)visibilidade nas mídias sociais. Complementarmente, em perspectiva do interesse público, evidenciamos que tais estratégias também são empregadas por organizações para fins que não são orientados pela ética e, mesmo, para ações ilícitas.

Palavras-chave: Comunicação organizacional. interesse público. mídias sociais. estratégias. (in)visibilidade.

\section{Abstract}

In this paper, we discuss about organizational communication with the objective of highlight strategies triggered by organizations with a view to reduce and/or direct their (in)visibility in social media and problematize such practices in the perspective of the public interest. To do so, we used data from a survey conducted by Da Silva (2018), which shows a set of seven strategies used by 
organizations operating in Brazil to manage their (in)visibility on social media. Complementarily, in the public interest perspective, we show that such strategies are also used by organizations for purposes that are not guided by ethics and, even, for illegal actions.

Keywords: Organizational communication. public interest. social media. strategies. (in)visibility.

\section{Resumen}

En este artículo, discutimos la comunicación organizacional con el objetivo de evidenciar las estrategias activadas por las organizaciones con la intención de reducir y/o conducir su (in)visibilidad en las redes sociales y problematizar tales prácticas en la perspectiva del interés público. Para hacerlo, utilizamos datos de una encuesta realizada por Da Silva (2018), que muestra un conjunto de siete estrategias utilizadas por organizaciones que operan en Brasil para gestionar su (in)visibilidad en las redes sociales. Complementariamente, en la perspectiva del interés público, mostramos que dichas estrategias también son utilizadas por organizaciones con fines que no están guiados por la ética e, incluso, por acciones ilícitas.

Palabras clave: Comunicación organizacional. interés público. redes sociales. estrategias. (in) visibilidad.

\section{Questões introdutórias}

Os estudos brasileiros sobre estratégias ${ }^{1}$ de comunicação organizacional nas mídias sociais $^{2}$, considerando o atual contexto midiático, por um lado, tendem a asseverar a importância de as organizações estarem visíveis e mesmo a assegurar a impossibilidade de não estarem visíveis nessas mídias e, por outro lado, inclinam-se a desconsiderar o fato de que a visibilidade não é, necessariamente, o único propósito das organizações nessas ambiências. Se é fato que a visibilidade ampliada de sujeitos e organizações nas mídias sociais foi instituída como imperativo do tempo presente, também é incontestável que essa situação nem sempre é desejada pelas organizações.

Nessa direção, por exemplo, em situações em que a circulação de sentidos sobre algum assunto, aspecto e/ou fato disser respeito a uma dada organização sob um enfoque não desejado, desfavorável e/ou se chocar com os sentidos projetados e acionados no âmbito da “organização comunicada”3 (BALDISSERA, 2009), é provável que ela operacionalize ações

1 As estratégias, compreendidas como práticas sociais (BULGACOV; MARCHIORI, 2010), situam-se no âmbito das interações entre sujeitos e, portanto, não se constituem em estruturas estáticas e lineares (PÉREZ, 2012). Assim, por mais que as organizações desejem, não podem controlar cenários; podem, sim, atuar e interferir neles de modo mais ou menos acertado, e em diferentes perspectivas.

2 Compreendemos que a expressão contempla não apenas os sites de redes sociais, focados em relacionamento, em troca, mas também as mídias de compartilhamento de vídeos, imagens, que permitem, mas não priorizam, o estabelecimento de uma relação. Estamos nos referindo a espaços como Facebook, Twitter, Instagram, YouTube, dentre outros.

3 Conforme Baldissera (2009), a comunicação organizacional pode ser compreendida sob três dimensões: a "organização comunicada", a "organização comunicante" e a "organização falada”. A "organização comunicada" consiste na fala autorizada (processos de comunicação autorizados) para dar-se a ver, dizer de si aos públicos, circular informações, administrar a organização etc. Também diz respeito "[...] àquilo que a organização seleciona de sua identidade e, por meio de processos comunicacionais (estratégicos ou não), dá visibilidade objetivando retornos de imagem-conceito, legitimidade, capital simbólico (e reconhecimento, vendas, lucros, votos etc.)” (BALDISSERA, 2009, p. 118). 
estratégicas para a redução de sua visibilidade em perspectiva de sair do centro da cena. Nos casos avaliados como mais graves, é possível que implemente estratégias mais sofisticadas (ou mesmo drásticas), seja para neutralizar os sentidos em circulação, gerar fatos que possam atrair a atenção dos públicos para outras questões, dificultar o acesso a informações e/ou reduzir ou omitir sua responsabilidade pela situação. Esses movimentos estratégicos revelam o desejo de invisibilidade da organização e de opacidade para algumas de suas práticas, em determinadas conjunturas.

Quando o contexto é de grande instabilidade, como o atual, em que crises de diversas ordens pautam os noticiários, e gestores e organizações figuram em escândalos midiáticos, uma das estratégias organizacionais tende a ser a de evitar associações a temas polêmicos, tabus (exceções feitas às organizações que têm essas associações como componentes de suas estratégias), e a agir para adentrar regiões de sombra da arena pública midiática ou, ainda, retrair-se o máximo possível para a esfera do privado. Cabe observarmos que esse comportamento, que é postura comum para organizações com práticas ilícitas e/ou não éticas, produtos e serviços inapropriados e/ou ilegais, também pode ser adotado por organizações corretas, éticas e que agem conforme a legislação. Nessas condições, não ser citada, não ser referenciada, estar em região de opacidade, constitui-se em valor medular, pois evita significação negativa, de modo que a restrição da visibilidade se apresenta como uma alternativa estratégica de desvinculação de práticas, situações e temas considerados periclitantes.

Diante disso, neste texto, temos os objetivos de evidenciar estratégias acionadas pelas organizações em perspectiva de reduzir e/ou direcionar sua (in)visibilidade nas mídias sociais, bem como problematizar tais práticas em perspectiva do interesse público ${ }^{4}$. Cabe destacarmos, desde aqui, que não se trata de simplesmente condenarmos tais práticas estratégicas, mas de problematizá-las à medida que o ofuscamento que provocam pode se contrapor ao direito de os públicos, poder público e sociedade acessarem informações sobre as organizações e suas práticas, especialmente quando, para atenderem os interesses organizacionais, dentre outras coisas, deslegitimam ou ocultam fatos de interesse público, ou, ainda, apresentam versões parciais sobre eles, procurando instituí-las como as "verdades”.

Com essa orientação, partimos dos pressupostos do interacionismo simbólico (MEAD, 1967, BLUMER, 1980) como potente aporte para o estudo das estratégias acionadas pelas organizações nas interações que realizam nas mídias sociais, considerando que essas interações são “[...] um agir comum, marcado pela mútua afetação e permeado por gestos significativos [...]” (FRANÇA, 2008, p. 90). Supõe as relações e a significação. Portanto, em perspectiva comunicacional, não se trata apenas de estímulo-resposta, de reciprocidade (um indivíduo afetar e ser afetado pelo outro), importa a reflexibilidade, isto é,

4 A noção assumida de "interesse público" remonta à dimensão social dos sujeitos, do (con)viver em sociedade. Está relacionada a entendimentos que partam do coletivo e, desse ponto de vista, congreguem/contemplem as opiniões majoritárias ou os valores da ética e da normatividade democrática. 
É a consciência dos sentidos inscritos nos gestos que nos torna capazes de selecioná-los e de antecipar as respostas de nosso interlocutor; é uma igual consciência deste último que lhe permite reagir seletivamente ao gesto recebido, fazendo de sua resposta um novo gesto que vai incidir retroativamente sobre $o$ primeiro, e assim sucessivamente (FRANÇA, 2008, p. 91).

A partir dessa compreensão, atentando para nosso objeto, podemos afirmar que quanto mais as organizações conhecerem seus públicos (domínio de seus códigos culturais e informações sobre seu comportamento político, por exemplo), provavelmente, mais saberão usar tais informações tanto para se movimentarem em direção de obter mais visibilidade, quanto para se afastarem das regiões de luz e de grande exposição pública. Entretanto, isso não significa admitir que as interpretações que os indivíduos realizarão possam ser predeterminadas por elas, pois existem os gestos de experiência desses indivíduos.

Nesse sentido, cabe recuperarmos, aqui, as três premissas do interacionismo simbólico, conforme Blumer (1980, p. 119): “[...] os seres humanos agem em relação ao mundo fundamentando-se nos significados que este lhes oferece”; os significados dos elementos são "[...] provenientes da ou provocados pela interação social que se mantém com as demais pessoas"; e os “[...] significados são manipulados por um processo interpretativo (e por este modificados) utilizado pela pessoa ao se relacionar com os elementos que entra em contato.” Consequentemente, não se trata de algo linear, mas de permanente intervenção dos indivíduos na (re)construção da significação do mundo. Complementarmente, vale ressaltar que nas relações comunicacionais também importa o mundo objetivo, a dimensão prática do fenômeno comunicacional.

Assim, atentando para a comunicação que se materializa nas mídias sociais, importa a perspectiva sociotécnica ${ }^{5}$. A significação construída não está dissociada das tecnologias, dos contextos, das intenções e das estratégias atualizadas pelos indivíduos e organizações que participam das interações. Além disso, a partir das teorizações de Goffman (2009), assumimos que as ambiências das mídias sociais são espaços de apresentação (dar-se a ver) e representação/performance para indivíduos e organizações, que podem ser situações de "atuação sincera" ou de "atuação cínica”. Considerando o imperativo da visibilidade e da estratégia para as organizações em contexto de profundas disputas simbólicas, em tensão com o discurso da transparência, da ética e da interdependência sistêmica, as representações cínicas tendem a assumir centralidade, conforme podemos comprovar a partir dos dados empíricos que acionamos neste trabalho.

Em relação a tais dados, desde aqui, é preciso ressaltarmos que, originalmente, foram coletados para a pesquisa de Da Silva (2018), com entrevistas semiestruturadas. Foram realizadas 14 entrevistas com 17 representantes ${ }^{6}$ de 14 agências de diferentes

5 Por "sociotécnica” compreendemos a articulação entre os sistemas social e tecnológico, particularmente em perspectiva das tecnologias de informação e comunicação.

6 No total foram realizadas 14 entrevistas. Porém, em três agências, as entrevistas ocorreram com dois profissionais. 
portes - pequenas, médias e grandes agências. O estudo envolveu sujeitos que atuam no assessoramento a organizações, especificamente no que se refere à presença nas mídias sociais. Entendemos que essas agências (e seus profissionais) são centrais para a reflexão proposta, pois detêm conhecimento sobre técnicas/caminhos para reduzir a visibilidade das organizações nas mídias sociais.

A definição dos informantes, conforme Da Silva (2018), obedeceu aos seguintes critérios: ser uma das 176 agências filiadas à Associação Brasileira de Agentes Digitais (Abradi - segundo semestre de 2017), principal entidade nacional com foco em comunicação digital; oferecer serviços vinculados às mídias sociais; ser acessível aos pesquisadores; e estar disponível e interessada em participar da pesquisa. Os dados, analisados com a técnica de análise de conteúdo (BARDIN, 2011), evidenciaram as principais estratégias implementadas por organizações quando prevalecia o desejo de invisibilidade ou de redução/direcionamento da visibilidade nas mídias sociais.

Quando da realização das análises, Da Silva (2018) seguiu as fases propostas por Bardin (2011), que estão organizadas em três polos: a pré-análise, a exploração do material e, por fim, o tratamento dos resultados (a inferência e a interpretação). Após a pré-análise, que envolve a preparação do material (transcrição dos relatos coletados), Da Silva (2018) partiu para a exploração dos conteúdos, entendido como a fase mais exaustiva do processo. Nesse ponto, foram criadas as codificações e categorizações, a partir do agrupamento de sentidos próximos e complementares com fins à criação de categorias de análise?.

\section{Comunicação organizacional e desejos de (in)visibilidade nas mídias sociais}

Visibilidade é pressuposto de existência pública. Na "sociedade da autopromoção" (THOMPSON, 2008), por um lado, experimentamos a potencialização das possibilidades de expressão em público, de estarmos na arena de visibilidade e, por outro lado, tendemos a nos tornar muito dependentes dela. De acordo com Trivinho (2011, p. 113 - grifo do autor), tratase "[...] de uma existência (pessoal, grupal, governamental, corporativa etc.) inteiramente condicionada à aparição na visibilidade mediática”, pois que o ethos da atual civilização reivindica a presença dos sujeitos para a alteridade “[...] independentemente de ela conceder ou não a atenção requerida”; assim, consiste em “(super)expor-se ou tornar-se visível” para "[...] existir de alguma forma (como simulacro) perante o conjunto dos sentidos percepcionais da alteridade".

De modo complementar, Trivinho (2011, p. 115-116) alerta que não se trata de simples vontade de tornar-se visível, pois que há o “desejo do único”, “[...] o desejo do domínio [...] de algum centro de cena mediática [...]”; há nesse desejo “[...] a pulsão ordinária de encenação solo e socialmente reputada em dado contexto de pertencimento (concreto ou imaginário)”. Portanto, nesse processo, simultaneamente, atualizam-se duas deslocações: a do desejante

7 No artigo, a partir dos objetivos estabelecidos, é priorizada a exibição das categorias, mas a documentação de todas as etapas da análise de conteúdo (BARDIN, 2011) pode ser consultada em Da Silva (2018). 
a ocupar o centro da cena e, consequentemente, a daquele (indivíduo, organização, público etc.) que é forçado a afastar-se de tal centro, seja para compartilhar a luz ou para moverse para as regiões periféricas ou, ainda, para sair de cena. Conforma-se, dessa maneira, ambiente de tensões, disputas, associações, dissociações e movimentações estratégicas. Até porque, conforme ressalta Sodré (2015, p. 19), atualmente, “[...] a imagem de um indivíduo agrega valor econômico na medida de seu incremento técnico: amplitude do espelhamento e da atenção pública”.

Particularmente pelas tecnologias de informação e comunicação, as disputas por ocupar um bom espaço na cena pública, por visibilidade, conforme destacou Thompson (2008), assumiram avultada importância por se realizarem em ambiente com maior fluxo de informações (mais intenso), com aumento exponencial do número de indivíduos que tomam parte nas redes comunicacionais (mais extensivo), e, diretamente relacionado com essas características, por ser menos controlável, à medida que nos ambientes digitais, dentre outras coisas, é mais dificultoso encobrir ações, prever desdobramentos e repercussões e regular a circulação de sentidos e informações. Então, além de as tecnologias terem ampliado as possibilidades de expressão e de circulação de informações, também conformaram ambiência para que qualquer coisa (bem, ação, ideia, comportamento, organização etc.) esteja sujeita a receber visibilidade e para que essa visibilidade, com muito de imponderável, escape aos desejos de indivíduos e organizações de deterem seu controle (BALDISSERA, 2017).

Ao refletirmos sobre essa configuração em articulação com os propósitos e conveniências de performar bem (como ação consciente) na arena pública, temos que, diferentemente do que é propagado, nem sempre indivíduos e organizações desejam visibilidade. Em perspectiva contrária, podemos afirmar que em várias situações, os desejos são de redução da visibilidade ou, mesmo, de invisibilidade midiática. Por diversos motivos, nem tudo pode ser apresentado em público. Dentre as razões estão as de caráter privado, estratégico e/ou de segurança, e lícitas, mas também as ilícitas, de diferentes tipos. Então, sob o imperativo da visibilidade, a ordem social, que se define “transparente”, como afirma Sodré (2015), está em confronto com o secreto, com o que não é mostrado, com o que é escondido.

Se no âmbito da gestão pública dos Estados democráticos a publicidade é um princípio fundamental - e o segredo é a exceção (segredo oficial) -, conforme destaca Bobbio (2015), pois é direito fundamental dos cidadãos acessarem informações, o mesmo não vale para os assuntos privados (por exemplo, um segredo comercial). Independente do tipo, ainda de acordo com o autor, o segredo constitui-se em poder invisível, atualizado de diferentes formas e relações com o poder visível, em perspectiva de prudência nas relações políticas.

No plano da comunicação organizacional, compreendida como "processo de construção e disputa de sentidos no âmbito das relações organizacionais” (BALDISSERA, 2008, p. 33), particularmente sob o prisma da “organização comunicada”, a regra da prudência tem seu emprego estratégico para "o dizer e o não dizer, o não dizer tudo, mas somente uma parte, o silenciar, o omitir, a reticência” (BOBBIO, 2015, p. 54). Dessa maneira, considerando os vários graus possíveis de opacidade entre o visível e o invisível, 
as decisões sobre o que deve ser visibilizado, quando, por qual público e em que níveis pressupõem exercícios de poder. Entretanto, se isso vale para a comunicação organizacional autorizada (“organização comunicada”), o mesmo não se aplica para a comunicação que se materializa na dimensão da "organização falada”" (BALDISSERA, 2009), que se realiza fora dos ambientes de domínio da organização e escapa aos seus desejos de controle.

Porém, ao atentarmos especificamente para o âmbito da "organização comunicada”, foco deste estudo, a aplicação da regra da prudência se atualiza no gerenciamento das informações que a organização deseja fazer circular (prioritariamente ${ }^{9}$, para quem, onde e quando), e, em nível de mais sofisticação estratégica, para a gestão de sentidos, isto é, para a seleção e circulação de sentidos, por exemplo: ofertas de "imagens de si” - ethos discursivo, conforme Maingueneau (2008), bem como para as orientações, disputas e/ou monitoramento das interpretações de tais sentidos e, ainda, para as aferições das apropriações que os diferentes públicos realizam. Exemplar é a estratégia de "gerenciamento de impressões" (WOOD JR., 2001, p. 153), que consiste na realização de um conjunto de análises e filtragens (oportunas à organização, e ‘adequadas” a requisitos morais, normatizações, códigos sociais e julgamentos sensíveis dos públicos), antes da circulação de conteúdos, para ampliar a potência de produzirem boas impressões, mesmo que não seja possível determinar tais resultados.

Então, entre os extremos da visibilidade e da invisibilidade, temos amplo número de possíveis graus de transparência e opacidade. Assim, por um lado, a atual ordem social do transparente tende a se efetivar à medida que indivíduos e organizações almejam e disputam visibilidade, complementada pela vontade de indivíduos e de públicos de 'verem' e por tecnologias que tornam isso possível, e, por outro lado, o fato de que organizações e indivíduos também podem desejar o segredo, a invisibilidade para si e/ou para suas ideias e ações, seja essa invisibilidade constante, apenas em algumas situações e/ou para algumas questões.

A este ponto, para prosseguirmos, importa destacarmos que as mídias sociais têm assumido cada vez mais relevância nas estratégias de comunicação organizacional. E, considerando a gestão dos níveis de (in)visibilidade, de modo simples, podemos afirmar que a invisibilidade nessas ambiências consiste em não estar visível aos públicos, estar oculto, estar em segredo. Entretanto, para além da simples não presença, é preciso atentarmos para o fato de que, dentre outras coisas, os públicos pressionam as organizações para que se façam presentes, as organizações precisam estar presentes para dizerem de sua existência e realizarem suas transações (de diferentes ordens), e/ou, ainda, a legislação pode exigir que elas exponham informações e realizem determinados pronunciamentos. Portanto, a invisibilidade nessas ambiências considera as situações em que algo, alguém ou alguma

8 Nessa dimensão, conforme Baldissera (2009), estão contemplados os processos de comunicação que se materializam fora do ambiente organizacional (espaço físico da organização, suas redes sociais, sua página na internet etc.), portanto fora dos domínios da organização, mas que se referem a ela. Exemplos dessa comunicação são as conversações sobre uma dada organização que ocorrem nas redes sociais de diferentes indivíduos, sindicatos, ONGs.

9 O termo 'prioritariamente' é empregado para destacarmos o fato de que as informações, uma vez em circulação, por pressuposto, não mais podem ser controladas pela organização. Em perspectiva disjuntiva, os diferentes interagentes podem apropriar-se e fazer diferentes usos delas, independentemente dos desejos da organização que, no máximo, pode empreender estratégias de monitoramento e agir no âmbito da organização comunicada. 
coisa não está visível ou não pode ser visibilizado por alguém (vidente), por um público e, mesmo, pelos mecanismos de busca na internet, ou que fica relegado a um segundo plano por não ter relevância sociotécnica. Isto é, estar em região de não visibilidade, não ter significância sociotécnica ${ }^{10}$, agir para sair das regiões de visibilidade e lançar sombras sobre o que não deseja visibilizar são algumas das perspectivas e ações para a invisibilidade. Por sua vez, com as noções de redução/direcionamento da visibilidade damos relevo aos desejos das organizações de diminuírem os graus de visibilidade de algo e, também, de indicarem o que deve se tornar relevante e visível.

Como veremos na sequência, são várias as estratégias, ações e técnicas em perspectiva de reduzir/direcionar a visibilidade e para as intenções de invisibilidade. E, a partir das reflexões de Bobbio (2015), podemos afirmar que o segredo e a redução da visibilidade de algo caracterizam as questões e ações da esfera privada e das estratégias de negócios; o que não significa que sejam, necessariamente, ilícitas. Essas questões passam a ser problemáticas quando esse poder invisível flerta com a ilicitude ao estabelecer relações com o poder visível, como quando decisões de interesse público são tomadas na invisibilidade, quando algo é mascarado para uma apresentação pública (dados de um balanço social, por exemplo), e quando a linguagem é usada para excluir o público por interesses escusos.

Essa problemática parece ser acentuada à medida que se evidenciam práticas organizacionais como a "[...] tentativa de plantar notícias falaciosas, a criação de falsos acontecimentos, o ato de espalhar boatos e rumores, a simulação de públicos ou situações que podem influenciar os públicos, a criação de organizações de fachada para disseminar informações” (HENRIQUES; SILVA, 2014, p. 4), pois sinalizam o risco potencial aos públicos que dificilmente dispõem de informações e técnicas que lhes permitam desvelar tais movimentos e suas intencionalidades. Complementarmente, Silva (2013) atentava para o fato de que muitas manifestações em fóruns de debates e salas de bate-papo, especialmente em períodos eleitorais, tornaram-se costumeiramente associadas a essas práticas. Não por acaso, de acordo com Henriques e Silva (2014, p. 7), "nas últimas duas décadas, as principais agências de relações públicas do mundo foram alvo de denúncias sobre a utilização” de técnicas de astroturfing ${ }^{11}$ para diversas organizações.

Cabe ressaltarmos que sujeitos e organizações encontraram, nas ambiências da internet, vigorosos meios para efetivarem e potencializarem essas práticas. Além disso, não são raras as vezes em que são publicizadas como sendo de transparência (importante valor no contexto atual, e com forte carga simbólica positiva), mas que, de fato, consistem em um fazer parecer transparente mediante a conformação (manipulando e/ou subtraindo informações) e a circulação de versões sobre algo e/ou alguma coisa que, em perspectiva dos

10 Dentre outras coisas, consideram-se as estratégias de aplicação intencional das boas práticas de visibilidade em sentido contrário para que algo não tenha ou perca relevância sociotécnica e, portanto, não obtenha ou perca visibilidade pública.

11 Astroturfing são "estratégias complexas formuladas para criar a impressão de que existe um público se manifestando como uma forma de influenciar a opinião pública” (SILVA, 2013, p. 15). Em perspectiva de verossimilhança, a um só tempo, essa prática mascara os reais patrocinadores da ação e faz-parecer/crer que se trata de um movimento espontâneo de algum público. Assim, como prática de manipulação e falaciosa, visa gerar a sensação de legitimidade e de movimentos genuínos. 
efeitos de verossimilhança, produzam a significação de transparência (e suas consequências) ao tempo em que dissimulam as estratégias e intenções dos que as realizam. Temos, então, que práticas semelhantes podem ser empregadas como estratégias lícitas e éticas ou, no limite, como práticas não éticas e/ou ilícitas. A seguir destacamos algumas das estratégias que têm sido empregadas, em diferentes perspectivas, por organizações e agências de comunicação digital no Brasil.

\section{Estratégias para a redução/direcionamento da visibilidade e invisibilidade nas mídias sociais}

De acordo com Da Silva (2018), são sete as principais estratégias ${ }^{12}$ (Quadro 1) que têm sido empregadas por organizações com atuação no Brasil (particularmente através de suas agências de comunicação digital), tencionando gerenciar seus níveis de visibilidade no âmbito das mídias sociais. Dentre elas, algumas têm caráter preventivo (evitar situações críticas e crises) e outras, efetivamente, são práticas (sempre como tentativas) para mitigar impactos de algo negativo para a organização, por vezes mediante o emprego de técnicas bastante sofisticadas, com alto grau de profissionalização. Essas estratégias podem ser agrupadas sob três principais propósitos: diagnosticar níveis de (in)visibilidade, reduzir e/ou direcionar a visibilidade, e tornar invisível (DA SILVA, 2018).

Acionadas em diferentes ordens, conexões e temporalidades, as estratégias têm fertilidade para conformarem variados arranjos em perspectiva de atenderem as necessidades e/ou desejos das organizações nos diversos contextos. Nesse sentido, é provável que elas, em situações mais complexas, particularmente quando se trata de desvincularem-se de temas/fatos mais sensíveis aos públicos, materializem mais do que uma estratégia, de modo articulado, objetivando aumentar a potência das ações e as probabilidades de atingirem os resultados desejados.

Quadro 1 - Estratégias para o gerenciamento da (in)visibilidade nas mídias digitais

\begin{tabular}{|l|l|l|l|}
\hline Intenção & Estratégias & Ênfases & Escopo \\
\hline \multirow{2}{*}{$\begin{array}{l}\text { Diagnosticar } \\
\text { níveis de (in) } \\
\text { visibilidade }\end{array}$} & $\begin{array}{l}\text { Monitorar } \\
\text { situações- } \\
\text { problema }\end{array}$ & Identificar riscos & $\begin{array}{l}\text { Prevenir-se frente possíveis crises ou da } \\
\text { visibilidade de pautas 'negativas'; antecipar- } \\
\text { se no planejamento de possíveis intervenções. }\end{array}$ \\
\cline { 3 - 4 } & $\begin{array}{l}\text { Acompanhar crises e } \\
\text { seus desdobramentos }\end{array}$ & $\begin{array}{l}\text { Sistematizar mecanismos de atenção às } \\
\text { situações-problema; atentar para os 'agentes } \\
\text { da crise', e acompanhar/compreender os } \\
\text { protagonistas. }\end{array}$ \\
\hline
\end{tabular}

12 Ressaltarmos que o emprego do termo ‘principais’ considera o fato de que, por um lado, essas foram as principais estratégias identificadas no estudo qualitativo e, por outro, reconhecemos que os entrevistados podem ter omitido informações sobre alguma estratégia, e, considerando a dinamicidade do campo, outras estratégias já podem estar sendo empregadas. 


\begin{tabular}{|c|c|c|c|}
\hline Intenção & Estratégias & Ênfases & Escopo \\
\hline \multirow{12}{*}{$\begin{array}{l}\text { Reduzir e/ou } \\
\text { direcionar a } \\
\text { visibilidade }\end{array}$} & \multirow{4}{*}{$\begin{array}{l}\text { Expressar } \\
\text { publicamente } \\
\text { a posição } \\
\text { institucional }\end{array}$} & $\begin{array}{l}\text { Apresentar o } \\
\text { posicionamento oficial }\end{array}$ & $\begin{array}{l}\text { Contrapor (em casos de alta relevância e } \\
\text { incidência ou com esse potencial) as versões } \\
\text { apresentadas pelos interlocutores. }\end{array}$ \\
\hline & & $\begin{array}{l}\text { Responder às } \\
\text { solicitações }\end{array}$ & $\begin{array}{l}\text { Responder a todas as solicitações dos } \\
\text { públicos (pressuposto: relação direta entre a } \\
\text { ausência de respostas e o aumento do alcance } \\
\text { de crises e pautas 'negativas'). }\end{array}$ \\
\hline & & $\begin{array}{l}\text { Ser ágil e } \\
\text { "transparente” no } \\
\text { atendimento às } \\
\text { solicitações }\end{array}$ & $\begin{array}{l}\text { Monitorar redes sociais e qualificar equipes } \\
\text { de atendimento para responder de forma ágil } \\
\text { e transparente (pressuposto: há relação direta } \\
\text { entre a lentidão de respostas e o aumento do } \\
\text { alcance de crises e pautas 'negativas'). }\end{array}$ \\
\hline & & $\begin{array}{l}\text { Ser resolutivo diante } \\
\text { das solicitações }\end{array}$ & $\begin{array}{l}\text { Resolver situações-problema no menor } \\
\text { tempo (pressuposto: há relação direta entre } \\
\text { a resolutividade dessas situações e a redução } \\
\text { do impacto de crises e pautas 'negativas'). }\end{array}$ \\
\hline & \multirow{8}{*}{$\begin{array}{l}\text { Baralhar } \\
\text { fatos e ênfases } \\
\text { para gerar } \\
\text { incompreensão } \\
\text { sobre uma } \\
\text { situação/fato }\end{array}$} & $\begin{array}{l}\text { Desviar o enfoque para } \\
\text { pautas positivas }\end{array}$ & $\begin{array}{l}\text { Oferecer sentidos que possam direcionar as } \\
\text { percepções sobre a organização. }\end{array}$ \\
\hline & & Gerar fatos & $\begin{array}{l}\text { Criar eventos/situações com potência para } \\
\text { atrair as atenções, direcionar a visibilidade e } \\
\text { gerar associações positivas. }\end{array}$ \\
\hline & & $\begin{array}{l}\text { Promover outros } \\
\text { enfoques a partir de } \\
\text { investimento financeiro }\end{array}$ & $\begin{array}{l}\text { Recorrer às possibilidades de espaços } \\
\text { publicitários para visibilizar conteúdos, nos } \\
\text { formatos e composições disponíveis, de modo } \\
\text { a direcionar o enfoque. }\end{array}$ \\
\hline & & $\begin{array}{l}\text { Infiltrar atores } \\
\text { organizacionais nas } \\
\text { discussões }\end{array}$ & $\begin{array}{l}\text { Infiltrar agentes para influenciar/alterar } \\
\text { o rumo das discussões, sem que sejam } \\
\text { percebidos como ‘representantes’ da } \\
\text { organização. }\end{array}$ \\
\hline & & ‘Comprar’ audiência & $\begin{array}{l}\text { Contratar interagentes que façam circular } \\
\text { sentidos desejados pelas organizações e se } \\
\text { contraponham a outras perspectivas. }\end{array}$ \\
\hline & & $\begin{array}{l}\text { Gerar incidência } \\
\text { ou contratar } \\
\text { influenciadores }\end{array}$ & $\begin{array}{l}\text { Persuadir e/ou contratar influenciadores } \\
\text { para assumirem e visibilizarem concepções } \\
\text { que corroborem discursos e ações da } \\
\text { organização. }\end{array}$ \\
\hline & & $\begin{array}{l}\text { Desequilibrar } \\
\text { concorrente(s) }\end{array}$ & $\begin{array}{l}\text { Desviar-se de visibilidade não desejada } \\
\text { empregando técnicas para (re)direcioná- } \\
\text { la para situações/aspectos negativos de } \\
\text { concorrentes. }\end{array}$ \\
\hline & & $\begin{array}{l}\text { Otimizar a visibilidade } \\
\text { desejada nos } \\
\text { mecanismos de busca }\end{array}$ & $\begin{array}{l}\text { Empregar técnicas de Search Engine } \\
\text { Optimization (SEO) para potencializar } \\
\text { versões da organização sobre temas e fatos. }\end{array}$ \\
\hline
\end{tabular}




\begin{tabular}{|c|c|c|c|}
\hline Intenção & Estratégias & Ênfases & Escopo \\
\hline \multirow{11}{*}{$\begin{array}{l}\text { Tonar } \\
\text { invisível }\end{array}$} & \multirow{3}{*}{$\begin{array}{l}\text { Desconsiderar } \\
\text { associações } \\
\text { / menções } \\
\text { “negativas" }\end{array}$} & $\begin{array}{l}\text { Esquivar-se de } \\
\text { pronunciamento ou não } \\
\text { se pronunciar }\end{array}$ & $\begin{array}{l}\text { Silenciar-se em relação a um assunto em } \\
\text { pauta e/ou sair de cena 'integralmente’ para } \\
\text { evitar visibilidade, foco e atenção. }\end{array}$ \\
\hline & & $\begin{array}{l}\text { Excluir ou ocultar } \\
\text { comentários e/ou } \\
\text { postagens }\end{array}$ & $\begin{array}{l}\text { Empregar técnicas para remover, das regiões } \\
\text { de visibilidade pública, comentários e } \\
\text { postagens com potência para comprometer a } \\
\text { organização. }\end{array}$ \\
\hline & & $\begin{array}{l}\text { Conduzir a conversação } \\
\text { para ambientes privados }\end{array}$ & $\begin{array}{l}\text { Efetivar as conversações em ambiências não } \\
\text { visíveis aos demais interlocutores. }\end{array}$ \\
\hline & \multirow{2}{*}{$\begin{array}{l}\text { Restringir a } \\
\text { visibilidade a } \\
\text { interlocutores } \\
\text { desejados }\end{array}$} & $\begin{array}{l}\text { Captar contatos a partir } \\
\text { de técnicas anônimas }\end{array}$ & $\begin{array}{l}\text { Acessar dados de interlocutores que se } \\
\text { mostrem relevantes para a organização } \\
\text { implementar estratégias de visibilidade } \\
\text { dirigida. }\end{array}$ \\
\hline & & $\begin{array}{l}\text { Selecionar segmentos } \\
\text { de públicos a partir de } \\
\text { suas movimentações e } \\
\text { comportamentos }\end{array}$ & $\begin{array}{l}\text { Constituir grupos de interlocutores que se } \\
\text { mostrem relevantes em função de objetivos, } \\
\text { necessidades ou desafios específicos. }\end{array}$ \\
\hline & \multirow{4}{*}{$\begin{array}{l}\text { Reduzir o } \\
\text { alcance de } \\
\text { conteúdos } \\
\text { ofertados pelas } \\
\text { organizações }\end{array}$} & $\begin{array}{l}\text { Antecipar-se na } \\
\text { apropriação de } \\
\text { mudanças de algoritmia } \\
\text { e formatos }\end{array}$ & $\begin{array}{l}\text { Acessar novas regras, parâmetros e lógicas } \\
\text { de algoritmia das mídias sociais a partir do } \\
\text { relacionamento com as organizações que as } \\
\text { controlam. }\end{array}$ \\
\hline & & $\begin{array}{l}\text { Explorar formatos de } \\
\text { conteúdo e horários } \\
\text { que costumam não } \\
\text { 'performar' bem }\end{array}$ & $\begin{array}{l}\text { Empregar formatos de conteúdo que, em } \\
\text { função das lógicas de algoritmia, tendem } \\
\text { a não ter êxito em termos de alcance e } \\
\text { engajamento. }\end{array}$ \\
\hline & & $\begin{array}{l}\text { Não aplicar técnicas de } \\
\text { 'tagueamento'13 }\end{array}$ & $\begin{array}{l}\text { Restringir a visibilidade de um conteúdo pelo } \\
\text { não uso das técnicas de 'tagueamento'. }\end{array}$ \\
\hline & & $\begin{array}{l}\text { Restringir a visibilidade } \\
\text { a um/poucos canal(is) }\end{array}$ & $\begin{array}{l}\text { Reduzir o alcance do conteúdo mediante o } \\
\text { não emprego de multimeios. }\end{array}$ \\
\hline & \multirow{2}{*}{$\begin{array}{l}\text { Estabelecer } \\
\text { políticas de } \\
\text { "conforto"14 }\end{array}$} & $\begin{array}{l}\text { Regrar a presença dos } \\
\text { empregados nas mídias } \\
\text { sociais }\end{array}$ & $\begin{array}{l}\text { Estipular e implementar diretrizes sobre } \\
\text { associações com a marca que empregados } \\
\text { podem realizar nas suas mídias sociais. }\end{array}$ \\
\hline & & $\begin{array}{l}\text { Definir previamente } \\
\text { temas que não devem } \\
\text { ser abordados }\end{array}$ & $\begin{array}{l}\text { Decidir antecipadamente sobre com quais } \\
\text { temáticas a organização não irá se envolver } \\
\text { ou manifestar. }\end{array}$ \\
\hline
\end{tabular}

Fonte: elaborado pelos autores com base na pesquisa realizada por Da Silva (2018).

13 Tagueamento consiste na definição de palavras-chave (descritores) que sintetizam o escopo de um conteúdo. Essa possibilidade contribui para que uma página seja mais bem ranqueada nos mecanismos de busca, por exemplo. Em algumas mídias sociais, como o Instagram e o Twitter, a visibilidade de uma publicação está fortemente condicionada às “tags".

14 A ideia de 'conforto', metaforicamente, representa inciativas/diretrizes que tenham o potencial de deixar as organizações em situações mais confortáveis. 
Conforme apresentamos no Quadro 1, a perspectiva “diagnosticar níveis de (in) visibilidade" compreende uma principal estratégia, que consiste em monitorar as situações que se apresentam como problemas à organização ou que têm potência para isso, isto é, trata-se de agir para identificar e entender os cenários, os contextos e os sentidos que conformam tais acontecimentos, eventos. Isso concerne ao pressuposto estratégico de que é preciso conhecer bem a situação para a tomada de decisão. Assim, o monitoramento para construir diagnósticos qualificados sobre riscos e crises envolvendo a organização é medular para a tomada de decisões em perspectiva de gerenciar, no âmbito da "organização comunicada”, seus níveis de visibilidade, ou seja, para definir, dentre outras coisas, o que deve ser publicizado, como, quando, por quanto tempo, em quais mídias, bem como para estabelecer, reforçar ou evitar associações com temas e fatos indesejados. Portanto, essa estratégia é central para os movimentos que as organizações realizam, seja em busca de mais visibilidade, seja para moverem-se em direção a regiões de mais opacidade, reduzindo os níveis de visibilidade e, no limite, adentrando espaços de invisibilidade nas mídias sociais (pelo menos sob determinados aspectos, fatos e temas específicos).

Em perspectiva estratégica, um nível mais complexo da gestão da visibilidade das organizações nas mídias sociais, atualiza a intenção de “reduzir/direcionar a visibilidade” (DA SILVA, 2018). Nesse sentido e conforme ressaltamos, as organizações usam o conhecimento obtido pelo monitoramento e análise das diferentes situações que as envolvem, no âmbito das mídias sociais (lógico, isso não significa dizer que se trate de apenas atentar para o que circula nessas mídias; sempre deve ser considerado em perspectiva de interdependência sistêmica), para definir o que deve se tornar relevante e visível, em perspectiva sociotécnica. Assim, procuram assumir a responsabilidade por definir o que 'merece luz' e o que deve ficar às sombras, a partir de seus desejos e interesses (reafirmamos que essa é a intenção das organizações, o que não significa que sempre se efetive).

Conforme destacamos no Quadro 1, para essa intencionalidade são acionadas duas principais estratégias. A primeira delas, “expressar publicamente a posição institucional”, compreende um conjunto de deliberações e ações para que as abordagens públicas sobre um tema/episódio se materializem a partir de vieses e concepções da organização, sobrepondose a outras perspectivas. Aqui, o pressuposto é o de que ao dar visibilidade à versão da organização sobre uma determinada situação-problema pode-se incidir sobre sua ressonância tendendo a reduzir a repercussão e, mesmo, exercer-se para influenciar as versões e sentidos que circulam nas mídias sociais. Vale observar que a não participação da organização em pautas que a envolvam e/ou a ausência de manifestações públicas tende a ser percebida pelos públicos como acomodação, desrespeito, indicativo de responsabilidade culposa e, no limite, como realização de algo ilícito. Assim, o silêncio (o não se pronunciar) pode potencializar embates e a repercussão sobre a situação-problema.

Por sua vez, a estratégia de "baralhar fatos e ênfases para gerar incompreensão sobre uma situação/fato” atende o desejo de organizações e agências em atrapalhar a compreensão dos públicos sobre determinada(o) situação e/ou fato. Assim, apresentam e movimentam 
outros fatos e/ou perspectivas que tenham potência para gerar confusão, distração, dúvida, desvios, enfim, turvar os fluxos de sentidos de modo a conturbar a compreensão dos públicos. É preciso atentarmos, desde aqui, que essa estratégia tem ampla potência de materialização de práticas não éticas, e escusas às questões de interesse público.

Com o propósito de "tornar invisível” nas mídias sociais, são quatro as principais estratégias adotadas por organizações e agências. Sob determinadas situações, após análise de contexto e dos prováveis desdobramentos daquilo que se apresenta, uma das estratégias é a de “desconsiderar associações/menções “negativas””, isto é, trata-se da não manifestação (não expressar o posicionamento institucional) e/ou do agir ignorando tais situaçõesproblema nas mídias sociais, procurando reduzir sua relevância. Noutras situações e/ ou de modo complementar, com a estratégia de "restringir a visibilidade a interlocutores desejados”, procuram limitar a visibilidade a um segmento (ou a segmentos) de públicos, de modo a invisibilizar algo aos demais interlocutores. Por sua vez, a estratégia de "reduzir o alcance de conteúdos ofertados pelas organizações” pode ser sintetizada como uma 'aparente' visibilidade, produzida pelo emprego de recursos sociotécnicos em perspectiva de “tornar invisível” - por exemplo, pelo não uso das técnicas de 'tagueamento'. A quarta estratégia, “estabelecer políticas de 'conforto”, tem como um dos pressupostos o fato de que, para evitar a (ou reduzir as probabilidades de) exposição pública de questões internas à organização, de modo indesejado, é necessário definir os temas acerca dos quais a organização não se manifesta/envolve, bem como estabelecer regras e orientar os empregados sobre como devem se posicionar nas mídias sociais sempre que realizarem alguma associação à organização.

\section{Estratégias para invisibilidade, redução/direcionamento da visibilidade e interesse público}

A este ponto, considerando as estratégias apresentadas, parece evidente que, se por um lado, algumas delas tendem a apenas ser empregadas em perspectiva de qualificar a gestão dos sentidos sobre a organização que circulam nas mídias sociais, como práticas para desempenhar uma boa apresentação de si, de dar-se a ver qualificadamente, como prática ética e responsável, por outro lado, em algumas delas há fortes indícios de seu emprego para encobrir concepções e ações que se chocam à perspectiva de responsabilidade das organizações, da ética e do direito dos públicos a acessarem informações sempre que se tratar de algo de interesse público. No limite, as estratégias para gerar invisibilidade podem encobrir práticas ilícitas ou mesmo criminosas. Portanto, se na dimensão do privado é pressuposto o emprego de estratégias e do segredo (sobre fórmulas, táticas, tecnologias, projetos, concepções, produtos e serviços, dentre outros), conforme destacamos, isso não significa admitir que tudo seja permitido e legítimo.

Nessa perspectiva, avaliamos que as apropriações das estratégias de invisibilidade e de redução/direcionamento da visibilidade podem levar as organizações a diferentes níveis 
de 'omissão em relação a' e/ou 'ocultamento de' assuntos e fatos - desde aspectos morais até questões legais - relevantes aos públicos, isto é, de interesse público. Cabe observamos que essa problemática é acentuada pelo fato de a vigilância sobre essas práticas abusivas, conforme Henriques e Silva (2014), ainda ser muito incipiente. É nesse contexto que informações de interesse público são escondidas e/ou distorcidas, que narrativas mentirosas são configuradas com aparência de verdadeiras para assumirem centralidade na arena pública, e que estratégias sociotécnicas são acionadas para atender interesses privados contrapondose ao interesse público.

Cabe ressaltarmos que a noção de interesse público compreende a perspectiva da aproximação/congruência de interesses individuais, que então assumem uma dimensão pública e se voltam para o "bem maior”, para o coletivo, para a sociedade como organismo que transcende a simples soma de suas partes (ARENDT, 2010). Portanto, o acesso às informações e os processos de comunicação pública apresentam-se fundantes, pois que em interações comunicacionais os sujeitos podem questionar práticas e concepções, expor argumentos, deflagrar discussões e realizar a crítica. É pela comunicação que temas e acontecimentos adquirem visibilidade, são debatidos e podem ser qualificados como de interesse público (BALDISSERA; SARTOR, 2016). E também é mediante processos de comunicação que esses temas são instituídos e assumem certos níveis de estabilização nas sociedades.

A essa luz, podemos afirmar que as práticas estratégicas para a redução de visibilidade e/ou para invisibilizar, não apenas revelam ambiguidades e distorções éticas, mas, em casos mais graves, também podem conformar ambiência fértil para a materialização de crimes corporativos. Nessa direção, podem revelar altos níveis de dissimulação e de mentira e motivar/induzir determinados comportamentos dos públicos a partir de falácias ou de informações “maquiadas” (manipuladas), muitas vezes apenas parcialmente reveladas sob o enfoque mais interessante às organizações, dentre outras coisas, desconsiderando regras morais e éticas e, mesmo, a legislação que sustentam o conviver em sociedade. O interesse público, assim, está ameaçado particularmente pelos detentores do poder, tornando-se objeto de manipulações e manobras (BORGES, 1996).

No âmbito das mídias sociais (foco deste estudo), deter poder não se reduz à ideia de poderio econômico, mas também o acesso às lógicas e gramáticas dessas mídias (por exemplo, funcionamento dos algoritmos) e o domínio no seu emprego. Sob a ordem social da "transparência” (SODRÉ, 2015), do imperativo da visibilidade, esse saber conforma-se em poder, dentre outras coisas, porque é pressuposto para ampliar as possibilidades de ação estratégica em perspectiva de regular os níveis de visibilidade e circulação de sentidos sobre a organização, suas práticas e concepções. E esse mesmo poder pode ser empregado para gerar zonas de pouca exposição pública e, mesmo, de invisibilidade de modo que ela tenda a se sentir liberada para agir apenas em perspectiva de seus interesses, mesmo que isso possa se traduzir em desprezar o interesse público.

Então, o problema não está nas estratégias (é normal que sejam empregadas pelas organizações), mas na forma como são acionadas e com que intenções. Entre a total 
transparência e o escondido (invisibilizado) são muitos os níveis de opacidade. Portanto, sempre que os interesses privados adentrarem o âmbito das questões de interesse público é fundamental que sejam freados (produzir algo como a suspensão do privado) para que seja possível a deliberação pública. Independentemente do tema e/ou fato, se for de interesse público (e a cada época a sociedade institui seus temas/fatos de interesse público), por si mesmo, exige transparência e compromisso com a comunicação pública, portanto, com a discussão na esfera pública.

O que está por trás das estratégias para invisibilizar fatos e/ou temas de interesse público são disputas sistemáticas para que nada ou pouco se sobreponha aos desejos e às estratégias de negócio das organizações. Por um lado, os recursos sociotécnicos viabilizam tais iniciativas e, por outro, tendem a ser potencializadas devido à incipiência de procedimentos que as coíbam. À luz da metáfora do teatro, em perspectiva das concepções de Goffman (2009), podemos afirmar que, muitas vezes, as movimentações que as estratégias representam são atos traduzidos em performances muito bem deliberadas e ensaiadas (cenas sequencialmente concebidas). Trazem para o centro do palco, para as zonas de visibilidade, as representações que buscam dissimular o que acontece nos bastidores. Sob o prisma da “manipulação de impressões” (WOOD JR., 2001), as mídias sociais são o palco (ou muitos palcos) no qual as organizações atuam a partir das associações e atributos idealizados e das expectativas da plateia/públicos.

\section{Considerações}

Entre a transparência organizacional gerada por processos de visibilidade nas mídias sociais e os múltiplos níveis de opacidade, até a invisibilidade do segredo, atualizam-se diferentes “jogos” estratégicos para a gestão de informações e de sentidos sobre a organização. Isso pressupõe a tomada de decisões sobre o que ela oferece aos públicos, quando, por quê e como, assim como o que deve ser baralhado, ofuscado, escondido. Embora os processos de significação não sejam lineares (LITTLEJOHN, 1982, FRANÇA, 2008), os domínios sociotécnicos (dentre outras coisas, conhecer e saber empregar os códigos socioculturais dos públicos, o acesso às gramáticas algorítmicas - ainda mais se de modo antecipado -, o deter as tecnologias e o poder contar com especialistas para empregá-las), no âmbito das mídias sociais, permitem que as organizações implementem estratégias (DA SILVA, 2018) com potência para se exercerem fortemente sobre a circulação, disputas e construção de sentidos sobre elas, suas concepções e práticas.

Porém, conforme observamos, essa mesma potência pode ser empregada para se sobrepor a temas e fatos de interesse público, especialmente pela manipulação e/ou ocultação de informações, pelo silenciamento e/ou baralhamento de dados e informações, pelo emprego de técnicas de astroturfing, e pelo desvio da atenção dos públicos para outras questões (fazer com que a visibilidade recaia sobre outros acontecimentos e/ou organizações). Nesse sentido, quantas informações concernentes ao interesse público devem ter sido ocultadas 
apenas na última semana? Quantas narrativas sem relação objetiva com fatos, mas que por atenderem interesses privados, circularam como verdades? Por que um assunto relevante que lemos em um site de mídia social não vem recebendo a devida atenção, embora seja extremamente grave?

Essa problemática exige mais atenção, pois que, conforme revelou o estudo de Da Silva (2018), o contexto é de alta profissionalização dos processos e apropriações de recursos sociotécnicos por organizações e agências de comunicação para implementarem estratégias de redução de visibilidade e de geração de invisibilidade nas mídias sociais, atenuando os níveis de transparência à sociedade ao tempo que geram a aparência de estarem sendo transparentes. A ética e o atendimento à legislação nem sempre orientam tais práticas, particularmente quando se constituem em obstrução dos objetivos privados. Não por acaso, atualmente, as fake news assumem centralidade no debate público, e seus impactos são percebidos nos diferentes sistemas, dentre eles o econômico, o político, o social, o cultural e o ambiental.

Diante disso, ressaltamos a importância de a sociedade (suas instituições) adotar mecanismos para, por um lado, fomentar a transparência, mediante a necessária publicidade àquilo que disser respeito ao interesse público e, por outro lado, desestimular/constranger práticas de redução de visibilidade e/ou para gerar invisibilidade pública que se contraponham a essa lógica. Mais do que simples publicidade, trata-se de comprometimento intersistêmico para o bem social maior. Assim, é preciso avançar com o debate público sobre o tema, bem como em termos de regulação dessas questões. Dentre outras coisas, isso também poderia fomentar a atenção da sociedade para o uso das mídias sociais e para o que circula por elas, seja em relação a sua segurança, confiabilidade e/ou consistência dos conteúdos.

\section{Referências}

ARENDT, H. A condição humana. 11. ed. Trad. Roberto Raposo. São Paulo: Forense Universitária, 2010. ASSOCIAÇÃO BRASILEIRA DOS AGENTES DIGITAIS (ABRADI). Disponível em: http://www.abradi. com.br/. Acesso: 28 jul. 2019.

BALDISSERA, R; SARTOR, B. A noção de interesse público e a perspectiva da comunicação. In: ROSÁRIO, N. M.; SILVA, A. R. Pesquisa, informação, comunicação. Porto Alegre: Sulina, 2016. p. 325-346.

BALDISSERA, R. Comunicação Organizacional: uma reflexão possível a partir do Paradigma da Complexidade. In: OLIVEIRA, I. L.; SOARES, A. T. N. (Org.). Interfaces e tendências da comunicação no contexto das organizações. São Caetano do Sul - SP: Difusão, 2008, p. 149-177.

BALDISSERA, R. Comunicação Organizacional na perspectiva da complexidade. Organicom (USP). São Paulo, v. 6, n. 10-11, p. 115-120, 2009. Disponível em: http://www.revistas.usp.br/organicom/article/ view/139013/134361. Acesso em: 12 out. 2019.

BALDISSERA, R. Comunicação organizacional e imagem-conceito: sobre gestão de sentidos no ambiente digital. In: RUÃO, T.; NEVES, R.; ZILMAR, J. (Orgs.). A comunicação organizacional e os desafios tecnológicos: estudos sobre a influência tecnológica nos processos de comunicação nas organizações. Porto/ 
Portugal: CECS, 2017, p. 71-87. Disponível em http://www.lasics.uminho.pt/ojs/index.php/cecs_ebooks/ issue/view/225/showToc. Acesso em: 14 nov. 2019.

BARDIN, L. Análise de Conteúdo. São Paulo: Edições 70, 2011.

BLUMER, H. A natureza do interacionismo simbólico. In: MORTENSEN, C. (Org). Teoria da comunicação: textos básicos. São Paulo: Mosaico, 1980. p. 119-138.

BOBBIO, N. Democracia e segredo. São Paulo: Editora Unesp, 2015.

BORGES, A. G. Interesse público: um conceito a determinar. Revista de Direito Administrativo. v. 205, 1996. Disponível em: http://bibliotecadigital.fgv.br/ojs/index.php/rda/article/view/46803. Acesso em: 23 ago. 2019.

BULGACOV, S.; MARCHIORI, M. Estratégia como prática: a construção de uma realidade social em processos de interação organizacional. In: MARCHIORI, M. (Org.). Comunicação e organização: reflexões, processos e práticas. São Caetano do Sul, SP: Difusão Editora, 2010. p. 149-166.

DA SILVA, D. W. Comunicação organizacional e as estratégias de invisibilidade e de redução/ direcionamento da visibilidade nas mídias sociais. 2018. 265f. Tese (Tese em Comunicação e Informação) - Programa de Pós-Graduação em Comunicação e Informação, UFRGS, Porto Alegre, 2018. Disponível em: http://www.bibliotecadigital.ufrgs.br/da.php?nrb=001072602\&loc=2018\&l=4e6a2daa8d0d211f. Acesso em: 10 jan. 2020.

FRANÇA, V. Interações Comunicativas: a matriz conceitual de G. H. Mead. In: PRIMO, A. et al. (Orgs). Comunicação e Interações. Livro da Compós 2008. Porto Alegre: Editora Sulina, 2008. p. 71-92.

GOFMANN, E. A representação do eu na vida cotidiana. Petrópolis: Vozes, 2009.

HENRIQUES, M. S.; SILVA, D. R. Vulnerabilidade dos públicos frente a práticas abusivas de comunicação empregadas por organizações: limitações para o monitoramento civil. Comunicação e Sociedade, v. 26, p. 162-176, 2014. Disponível em: https://revistacomsoc.pt/article/view/1152/1134. Acesso em: 18 out. 2019.

LITTLEJOHN, S. W. Fundamentos teóricos da comunicação humana. Rio de Janeiro: Zahar, 1982.

MAINGUENEAU, D. Cenas da enunciação. São Paulo: Parábola Editorial, 2008.

MEAD, G. H. Mind, self \& society: from the standpoint of a social behaviorist. Chicago: The University of Chicago Press, 1967.

PÉREZ, R. A. Las dimensiones de la estratégia. In: PÉREZ, R. A. Estrategias de comunicación. Barcelona: Ariel, 2012.

SILVA, D. R. O astroturfing como processo comunicativo: enquadramentos na manifestação encenada de um público. In: V CONGRESSO DA COMPOLÍTICA. Curitiba, 2013. Anais.... Disponível em: http://www. compolitica.org/home/wp-content/uploads/2013/05/GT06-Cultura-politica-comportamento-e-opiniaopublica-DanielReisDaSilva.pdf. Acesso em: 13 out. 2019.

SODRÉ, M. Do segredo ao público/privado. In: CASTRO, P. C. (Org.). Dicotomia público/privado: estamos no caminho certo? Maceió: EDUFAL, 2015. p. 13-24.

THOMPSON, John B. A nova visibilidade. Revista Matrizes, v. 1, n. 2, 2008. Disponível em http://www. revistas.univerciencia.org/index.php/MATRIZes/article/viewArticle/5230. Acesso em: 7 out. 2019.

TRIVINHO, E. Visibilidade mediática, melancolia do único e violência invisível na cibercultura. Revista Matrizes. a. 4, n. 2 (jan./jun. 2011). São Paulo: ECA/USP, 2011.

WOOD JR., T. Organizações espetaculares. Rio de Janeiro: FGV, 2001. 


\section{Diego Wander da Silva}

Doutor em Comunicação e Informação (UFRGS) e Mestre em Comunicação Social (PUCRS). Professor da Escola de Comunicação, Artes e Design - Famecos, na PUCRS. Membro do Grupo de Pesquisa em Comunicação Organizacional, Cultura e Relações de Poder (GCCOP/UFRGS) e do Grupo de Estudos Avançados em Comunicação Organizacional (Geacor/PUCRS). E-mail: diego. wander@pucrs.br.

\section{Rudimar Baldissera}

Doutor em Comunicação e Mestre em Comunicação/Semiótica. Na UFRGS, é docente do Departamento de Comunicação e pesquisador e professor do Programa de Pós-Graduação em Comunicação - apoio da Capes. Líder do Grupo de Pesquisa em Comunicação Organizacional, Cultura e Relações de Poder (GCCOP/UFRGS). Bolsista de Produtividade em Pesquisa (PQ) do CNPq. E-mail: rudimar.baldissera@ufrgs.br.

Recebido em: 10.06.2020

Aprovado em: 05.02.2021

Este artigo é publicado em acesso aberto (Open Access) sob a licença Creative Commons Attribution Non-Commercial (CC-BY-NC), que permite uso, distribuição e reprodução em qualquer meio, sem restrições, desde que sem fins comerciais e que o trabalho original seja corretamente citado. 